\title{
De todas las sangres: las aves en la mitología amazónica
}

\author{
María Chavarría Mendoza \\ Universidad Nacional Mayor de San Marcos, Lima, Perú \\ chava001@yahoo.com
}

Para André Marcel d'Ans, in memoriam

\begin{abstract}
RESUMEN
Casi todos los mitos etiológicos de la amazonia confirman que las aves cumplen un rol fundamental en la vida de los primeros pobladores. Son seres poderosos que pueden funcionar en distintos espacios o nichos ecológicos: la tierra, el agua y el cielo. Fueron quienes colaboraron en la obtención del fuego (Pano), en preservar la vida después del diluvio, fecundar a las mujeres cuando no había hombres (Harakabut) y más aún, en el pueblo ese eja (Takana), son responsables de elegir a los futuros chamanes o eyamitekua. Existen humanos que se desposaron con aves (Yine). Gracias a ellas, los muertos son protegidos para que puedan culminar su viaje hacia el otro mundo al encuentro de sus ancestros. No solo en la literatura oral las aves son protagonistas, sino también en el origen y supervivencia del chamanismo. Ni el tejido de las cushmas o ropas originales, ni los tocados sagrados puede supervivir sin la intervención prodigiosa de las aves. Estos mitos han sido analizados desde Lévi-Straus hasta el antropólogo brasileño Viveiros De Castro. En suma, este artículo presenta los roles más difundidos de las aves en el imaginario amazónico de muchos pueblos de la amazonía.
\end{abstract}

Palabras Clave: Mitología, mitos etiológicos, imaginarios, aves, pueblos amazónicos

\section{From all bloods: the birds in amazonian mythology}

\begin{abstract}
Almost all the etiological myths of the Amazon confirm that birds play a fundamental role in the lives of the first settlers. These are powerful beings that can function in different spaces or ecological niches: the earth, the water and the sky. It was those who collaborated in obtaining the fire, "Pano», in preserving life after the flood, fertilizing women when there were no men «Harakabut», and, moreover, in the town that was «Takana», they are responsible for choosing the future shamans or «Eyamitekua». There are humans who married birds «Yine». Thanks to them, the dead are protected so that they can complete their journey to the other world to meet their ancestors. Not only in oral literature birds are the protagonists, but also in the origin and survival of shamanism. Neither the fabric of the "Cushmas» or original clothes, nor the sacred headdresses can survive without the prodigious intervention of the birds. These myths have been analysed from Lévi-Straus to the Brazilian anthropologist Viveiros De Castro. In summary, this article presents the most widespread roles of birds in the jungle imagination of many Amazonian inhabitants.
\end{abstract}

KeYwords: mythology, etiological myths, Amazonian imaginary, birds, Amazonian inhabitants 


\section{Introducción}

Casi todos los mitos etiológicos de la amazonia confirman que las aves tuvieron y siguen teniendo un rol fundamental en la vida de la humanidad. Son seres poderosos pues funcionan en distintos espacios o nichos ecológicos: la tierra, el agua y el cielo y, además, son sensibles a los efectos del cambio climático.

Desde el comienzo de la vida, las aves han sido héroes y fuente de conocimiento. En este artículo presento ciertos roles de estos seres alados y su documentación en textos de la tradición oral de algunos pueblos de la Amazonía. Pero, previamente, es oportuno recordar que a falta de escritura, fueron representadas primeramente en la pintura corporal, rupestre, los petroglifos, la cerámica prehispánica, los telares e incluso las líneas del desierto de Nazca donde destaca la figura de un picaflor.

Una vez iniciada la conquista de América, el primer tratados sobre aves que se conoció fue del Obispo de Trujillo Martínez Compañón con su obra Imágenes y Textos de (17821799). Esta autoridad eclesiástica dirigió lo que fue el primer estudio sobre las aves peruanas. Según la investigadora Irma Franke en su blog, da cuenta de que esta investigación tuvo como resultado tres catálogos a saber: la Colección de Madrid que contiene 156 láminas que representan aves y 8 láminas de escenas o danzas que incluyen aves. Esta colección tiene un índice que proporciona los nombres comunes en castellano y/o quechua para cada ave. La Colección de Lima consiste de 54 láminas de aves y 4 láminas que representan escenas o danzas que incluyen aves. La otra publicación corresponde al vasco José Ignacio Lecuanda, en el Mercurio Peruano (1793-1794) con ilustraciones del francés Luis Thiebuat. El compendio de estas publicaciones contiene 51 aves o grupos de aves, en su mayoría picaflores y otra lista de otras 23 aves. Y finalmente el Quadro de Historia Natural, Civily Geográfica del Reyno del Perú (1799). Según Franke, este otro catálogo de la biodiversidad peruana fue recogido en el Perú e ilustrado por Thiebaut en Madrid (España) por encargo del mismo Lecuanda. Es considerada una enciclopedia pictórica o mural en la que se muestra una selección de imágenes de las acuarelas de Martínez Compañón acompañadas de cortos textos que son casi resúmenes de los publicados por Lequanda en el Mercurio Peruano. El Quadro contiene 88 representaciones de aves.

\section{Aves en el gran diluvio}

Todos los pueblos amazónicos y, en general, casi todas las culturas del mundo tienen como motivo inicial la historia de una lluvia aniquiladora o diluvio. Este desastre tiene por objeto finalizar una etapa donde el desorden y el caos ponen en peligro la supervivencia del orden existente. El origen de las lluvias torrenciales puede tener distintas causas, anuncia un desastre y luego un cambio. 
«Cuando llovió allí lejos» es un mito ese eja (familia Takana), donde inicialmente dos hermanos de nombre Noíja están pescando con barbasco, cuando observan que todos los peces conocidos como boquichicos (Prochilodus nigricans) se juntan en el hueco de un barranco. Estos peces se caracterizan por ser iliófalos, es decir, se alimentan de barro y están provistos de unos dientes viliformes que les permiten raspar el fondo del río. El caudal del río va subiendo a tal punto que los boquichicos, que normalmente están pegados a la tierra, son empujados por la fuerza del agua hacia el barranco. El barranco es concebido como un lugar cerrado al cual se accede por una puerta al igual que la entrada al agua, referencia encontrada en otros mitos. Es interesante observar que el texto seńala que los hermanos Noíja se paran en la «ventana del barranco». Estos hermanos son los pájaros «budusqui», en castellano regional. Claudia Gálvez-Durand (1994, P.20) los identifica como pertenecientes a la Familia Momotidae, especie Momotus momota. y conocido bajo el nombre de budusqui. Los hermanos ven que el barranco se está desmoronando y avisan a sus paisanos del peligro. Pero lo irreparable sucede, todo se derrumba y el agua cubre la tierra.

El paisaje sufre una transformación: «Todos desaparecieron. No quedó nada. Nadie más vino, nadie más se fue». El barranco ya no existe y, además, los sobrevivientes sufren su propia transformación, un paisano llamado Tsaja se convierte en Martín Pescador (Alcedo atthis). Esta hermosa ave se encuentra en casi todo el mundo y hay varias especies de ella en el Perú. Los hermanos Noíja, nuestros héroes se convierten en pájaros budusqui. Como recuerdo del desastre, sus patitas están pegadas. Todo el río Baawaja (hoy Tambopata) quedó borrado. El mito termina con estas frases.

Sus cadáveres ennegrecieron la tierra.

Las islas que antes había,

desaparecieron, ya no existían.

\section{Batsaikui,el árbol de origen de las aves y cómo fue que el picaflor y el tucán volaron juntos}

Este otro mito ese eja plantea un lugar de origen común para todas las aves. El árbol de origen o axis mundi se llamaba Batsaikui, allí se posaban todas las aves que hoy conocemos. Los relatores dijeron que antes las aves volaban por toda la selva, pero no se quedaban a pernoctar en cualquier sitio sino que todas regresaban a Batsaíkui, el árbol único. Si todas las aves pernoctaban en un solo árbol, durante el día esto provocaban un estruendo horrible, insoportable. Las quejas eran constantes y no había paz ni sosiego. La bulla es indicador de desorden, no hay silencio, todos cantan al mismo tiempo y no hay descanso. Es por ello que la gente indígena cuando viene a la ciudad no puede dormir en un comienzo por el exceso de luz y ruido. 
Imaginarse a todas las aves en un solo árbol producía jocosos comentarios entre el público que escuchaba el relato de mi grabadora. Otro evento paralelo sucede con Kua'i i 'picaflor' y Sokuéi 'pinsha' o tucán. El picaflor lleva en su pico una ramita o algo que en castellano regional se conoce como 'secana', el picaflor falla pues la secana pesa mucho, entonces el tucán lo ayuda pues tiene un pico más grande (y fuerte). «Muy chiquito era. No valía» dice el relator. Hay otro defecto que encuentran al picaflor. «Su pata no podía asentarse». Por donde iba Sokuei la pinsha, iba, también Kua’ii, el picaflor.

Allí mismo se caía, «Trrr, trrr, trrr»

Entonces, se produce el conjuro de Sokuei: «Trrrruuui, volando, volando, volando irás a chupar las flores». La interdicción permite establecer las funciones de Kua’i’i y la inauguración del orden. Kua'i'i y Sokuei se alejan del árbol de origen y se trasladan a otro río y hasta el día de hoy se los ve juntos.

\subsection{El patrón espacial y la noción de territorialidad}

La noción de territorio es inherente a todos los pueblos e igual sucede con las especies animales que también demarcan sus espacios. Para la gente de la Amazonía, hoy y siempre la lucha por preservar el territorio está en todas las plataformas de lucha, recuperar el espacio que necesitan para desarrollarse socialmente es un reclamo que implica recuperar la memoria del paisaje de los antepasados. El espacio conocido es lo que comparten y por ello es un elemento crucial del constructo llamado identidad y al que pertenecen también el sistema de parentesco, el idioma y la cultura. Al volar de regreso al árbol Batsaíkui, dicen que el picaflor anunciaba «Yioho kuei, kuei, kuei. Yioho kuei kuei kuei.» («Este es mi río. Este es mi río»).

En un comienzo, los narradores decían que el picaflor había dicho: «Este es mi pueblo. Este es mi pueblo». Sin embargo, esto no coincidía con nuestra traducción literal, pues la palabra kuei corresponde a 'río' y no a 'pueblo' que es un término occidental y moderno. La noción de pueblo hoy se asocia a conjunto de personas que tienen lazos de parentesco, comparten un mismo territorio, historia, idioma y costumbres. Antiguamente, la gente vivía dispersa y el patrón de asentamiento se identificaba por el río por donde circulaban y no por la tierra que está más asociado a las culturas andinas donde la llacta es el pueblo, mas no el río.

La repetición de «kuei kuei kuei» permite confirmar que hay una preceptiva estilística interna dentro de la oralidad, al igual que en los textos escritos. La repetición es empleada en la lengua con el fin de enfatizar una parte del discurso y también para crear un ritmo que evoque el canto del ave. ¿Por qué el picaflor insiste en repetir esto? Porque esta es la manera que tienen las aves de demarcar su territorio, señalando con su voz/canto cuál es su espacio. Frente a un número de aves que comparten un mismo espacio, el picaflor 
está señalando a las demás lo que es suyo. El mito traduce de una manera alegórica una observación empírica que los Ese Eja han hecho del comportamiento animal. La noción de la territorialidad de los animales no es muy distinta de lo que ocurre entre los hombres Kloper (1970).

Kua'ìi como picaflor va señalando su espacio y advirtiendo a los demás que este es el río donde vive. Si se considera que el relato se desarrolla en un tiempo donde recién se están estableciendo las diferencias, es deseable que se ordene el espacio de los que habitan este mundo.

\subsection{El picaflor como ser prodigioso}

Al igual que en otras culturas, el picaflor se destaca como un ser dotado de cualidades sobrenaturales que le permiten ir de este mundo al otro con cierta facilidad. Algo similar encuentra Santos-Granero (1991,P.113) entre los yánesha, donde Amaseñe’t y Aseñac son concebidos como mensajeros de los shamanes. Su presencia aparece en toda la amazonía. Entre los awajún de Perú, Jempue, el picaflor es quien roba el fuego al gigante Iwa y la paloma Yámpits se encarga de quitarle las semillas del frejol, maíz y maní para dárselas a los hombres quienes así conocerán la agricultura (Jordana1974).

\section{Las aves y el origen del fuego}

Todas las lenguas Pano cuentan con el mito de Yowashikonawa, el Inca mezquino. Este ser posee el fuego y los hombres viven sin poder cocinar su comida y sin tener hoguera donde calentarse en época de lluvias. En la versión recogida por d'Ans (1975) dentro de los kashinawa o huini kuin,el lorito Cherre se ofrece a robar el fuego. Tampoco había yuca. Todos se morían de hambre, Este fragmento también introduce el concepto de alienación donde los poderosos nos dan cosas que que no necesitamos.

Pero el tal Yawashikonawa accedía a las demandas de sus visitantes de manera muy peculiar. Si le pedían granos de maíz, los entregaba, ¡pero asados! ¿Cómo iban a brotar? En vano pues, los crédulos favorecidos esperaban la germinación. Cuando venían por los palos de yuca, los daba; pero antes, les cortaba las yemas; sembrados, nunca echaban hojas. De este modo procedía siempre: después de hacerse mucho de rogar, entregaba lo que nunca iba a crecer. Es que no toleraba ver sembrada ninguna otra chacra. ¡Era un verdadero mezquino!

Dentro del sistema de valores de los pueblos indígenas, el no saber compartir es el peor de los defectos que puede tener el ser humano, por ello la conducta de Yawashikonawa es censurable y este mito es ejemplificador. Primero, Shabon, la lagartija va a pedirle 
a la mujer del mezquino, los granos de maíz y ella se los niega. Pero en un momento de descuido en que la mujer va a hacer sus necesidades, Shabon se mete un granito en la boca. La mujer cuenta los maíces y al ver que falta uno, abre la boca de Shabon, «al abrírsela con rabia, le desgarró las mejillas. Desde entonces, la lagartija luce una enorme boca, hendida hasta las orejas». Luego, Yawashikonawa, al interrogarla le pide mostrar sus manos y de rabia le aplasta los dedos de ambas manos hasta darle forma actual que tiene las manos de la lagartija.

Le toca el turno a Chërë el lorito que por esa época tenía un pico grande como el tucán. Se acerca adonde estaba Yawashikonawa con su mujer y se ponía a llorar así: «Cherr cherr, cherr» molestando a los esposos mezquinos. Cansado de su llanto, Yawashikonawa le arroja un tizón para ahuyentarlo. El héroe lo recoge con su pico y se aleja volando, pero como la candela quema, invoca ayuda a sus compańeros y se desata una lluvia. Las otras aves lo cubren con sus alas para que Chërë el lorito culmine su proeza. Aquí se producen diferentes versiones para explicar el color del plumaje de las aves.

Los demás pájaros construyeron una verdadera pirámide de cuerpos emplumados sobre el fuego robado y lo protegieron así de la lluvia. Muy cerca del tizón estaba Shawan, el guacamayo rojo, que debe su color al contacto con el fuego vivo. Justo sobre él se puso Kain, el guacamayo cabezón, un poco menos rojo que él. Después, los demás pájaros sucesivamente, hasta terminar con Oka, el locrero; su cuerpo es completamente negro porque solo el humo alcanzó su plumaje.

Terminando su hazaña, Chërë el lorito deja el tizón en el hueco de un árbol capirona y corre al río para enfriar su pico. Al hacerlo, su pico se encorva, una parte se desprende y por eso su pico es corto y curvo. Desde esa vez se tiene fuego y los elementos para una agricultura de autoconsumo. La mezquindad es el antivalor de la sociedad amazónica y la solidaridad es la clave para desarrollarse como una sociedad inclusiva.

\section{De todas las sangres o cómo los paucares flechaban a los futuros shamanes}

Es común en muchas culturas amazónicas la necesidad de explicar el brillante colorido de la avifauna de su región. La mejor manera es hacerlo a través de historias que les han sido transmitidos por los ancianos y que es necesario contar a las siguientes generaciones. De acuerdo con lo que dice la ornitología occidental, el colorido profuso de ciertas aves ha sido desarrollado por algunas especies para suplir la falta de camouflage.

El repertorio mítico sudamericano explica el origen de los colores de las aves siguiendo dos tipos de patrones: a) por intervención de la sangre; b) por intervención 
del fuego a través de diversos agentes como el fuego mismo, los tizones, el humo y las cenizas.

En uno de los pocos trabajos que existen sobre este tema, Pressman (1991: 79) seńala que los colores de las aves son el resultado de haber sido pintadas por un agente externo como sangre, fluidos de órganos internos y principalmente el fuego como acabamos de relatar.

«De todas las sangres» alude a la diferente procedencia de los eyámitekua o shamanes en la mitología ese eja y destaca el carácter iniciador de las aves. Los paucares (Cacicus cela) son los dueños de este saber y lo trasmiten flechando a los hombres y haciéndolos sufrir. El paucar, ave de brillantes colores negro en el vientre y alas, pero amarillo en su larga cola, tiene unos fulgorosos ojos azules. Mide 28 centímetros y pesa aproximadamente 104 gramos. Los nidos de estas aves se ven a lo largo de todo el bosque, son especies de bolsas que cuelgan llamativamente de los árboles. Las plumas de los paucares son usadas en atuendos diversos, aretes, collares, coronas, etc. Se han encontrado plumas de loros, guacamayos y paucares en las telas, abanicos y demás adornos de culturas preandinas. Pero, además. el paucar es un ave privilegiada pues puede imitar el canto de otras aves. Entre los ese eja, se cree que el poder de la palabra es trasmitido por el paucar y por eso saben dar de comer sus sesos a los niños para que hablen bien su idioma.

El texto está estructurado en dos partes claramente definibles: en la primera, una serie de aves — paucares en su mayoría — atacan a los futuros shamanes, el relato provee información que permite justificar las características físicas actuales de las aves y una segunda, donde otras aves se forman a partir de la sangre que queda de la dura batalla. Es interesante anotar que los colores oscuros son de los paucares y los brillantes de los loros.

El relator anuncia: «Sangre de todas partes había: sangres amarillas, sangres azules, sangres rojas» y aquí se plantea la diversidad de colores de las aves que intervienen en el mito. En esta segunda parte, se explica el color intenso de Jaanee 'guacamayo bien rojo' —nótese el uso del intensificador $\{$-nee\}. Jaanee se habría bañado en la sangre roja. Igual pudo haber sucedido con el otro guacamayo Jahue sino fuera por otro evento que se introduce.

Sin embargo, la función que se atribuye a la sangre es diferente en la concepción amazónica según lo observado entre los Shuar de Ecuador por Von Hagen (1937: 160161) y citado por Pressman (1991). Este autor considera que para las sociedades occidentales, la sangre como líquido vital es lo más importante; sin embargo, para las sociedades amazónicas, es la sangre coagulada la que permite introducir cambios:

I noticed the great place that blood plays in the ceremonies of the Indian. The native does not consider blood in its material aspects as we do. We regard it as a liquid that 
circulates in accordance with the impulses given to it by the contraction of the heart. Its coagulation on leaving the body we recognize as a chemical action and a property common to all blood. But to the primitives, the coagulation is most important. For them, far from being a mere liquid without which life would not function, it is endowed with a great supernatural power. It is a vital principle of immeasurable potency. It has a magic virtue, and helps as a charm against witchcraft (81).

Es así como Jaanee se baña en la sangre, que ya debe estar en proceso de coagulación. Jawe tendría el mismo color encendido sino hubiera sido engañado por Jaanee quien le miente diciéndole que ha obtenido su color gracias al humo. Jawe cae en el engaño y pese a las advertencias de Sheshe, el lorito, se acerca al humo y al frotarse con la mano/ala entiznada, tińe su plumaje de color cenizo. "Al limpiarme con la mano me he ensuciado», cuenta Jawe.

\section{El intercambio de obsequios entre el tucán y el pájaro carpintero (Tradición oral awajún, recopilada en castellano)}

La incógnita de por qué las aves tienen plumaje diferente es explicada dentro de los pueblos awajún (Jívaro) como un intercambio de dones entre el tucán y el pájaro carpintero. Este es el motivo recopilador en castellano por el exmisionero jesuita José Luis Jordana (1974). El tucán admira el trabajo que realiza el pájaro carpintero al huequear los troncos con habilidad prodigiosa. El tucán sueña con tener un nido en un hueco tan bien hecho; en cambio, el pájaro carpintero, anhela tener un plumaje colorido pues sus colores son sosos. Entonces le propone al tucán hacer un intercambio.

-Mira, cuñado, si tú quieres que te regale mi nido, tú regálame las plumas de colores que tienes sobre tu cabeza que son muy lindas.

Entonces, el tucán le regaló al carpintero las plumas que tenía en su cabeza, en su cresta, y el carpintero le dio a cambio el nido que tanto quería el tucán, no sin antes pegarse las plumas en su cola. Es por eso que se ve volar a ambos amigos juntos. Como se podrá notar los nombres de los personajes aparecen solo en castellano pues Jordana (op. cit.) fue quien recopiló en una edición sencilla, la más grande colección de relatos aguarunas (awajún) y huambisas (hoy wampis) que apareció en una serie llamada Retablo de Papel, durante el gobierno del general Juan Velasco Alvarado. ${ }^{1}$

1 La editora Retablo de Papel era el sector del Ministerio de Educación orientado a las publicaciones masivas y consignó no solo auténticas piezas narrativas como de Adaneva e Inkarrí, recopilaciones de migrantes andinos viviendo en la capital para difundir la riqueza oral de los pueblos indígenas del Perú sino también obras importantes de las ciencias sociales como La sal de los cerros de StéfanoVarese. Nunca hubo otro gobierno que haya tratado de superar esta proeza. 


\section{Anamei, el árbol de la creación harakbut y el origen de todas las cosas}

Este mito fundacional ha sido transcrito y traducido por varios autores (Helberg, 1996; Gray, 2002; Dariquebe Jerehua s.f., Patiachi, 2015). De esta inmensa narrativa solo mencionaremos los episodios que tienen que ver con el poder creativo de las aves sobre todo lo existente. Se inicia en un momento en que la selva se encuentra en pleno incendio y todo está por desaparecer. Todos los animales son mansos. Hay una confusión total donde el agua y la comida tiene sabor amargo. Surgen los totos o entidades malignas y también los enemigos de los arakbut, los takas. A todos el fuego y el humo los invade.

Un ave, el loro Wehweh vuela alrededor de la gente y parece que va a aterrizar pero no lo hace, la gente observa que lleva en el pico una semilla, debe ser un mensaje. Las muchachas que debían ser vírgenes supuestamente, se echan, una a una, desnudas mirando el cielo, pero una a una van siendo descartadas por Wehweh. No eran vírgenes y el loro sigue volando con su semilla en el pico. Hasta que la nieta de una anciana que vive sola, se echa desnuda mirando al cielo y Wehweh posa la semilla en la vagina de la joven y de esa unión crecerá Anamei, el árbol de la vida. A este árbol que crece prodigiosamente trepan todos los que quieren escapar del fuego. Subieron las mujeres cargando a sus criaturas en el kusipe y detrás todos los seres vivientes. Luego viene un diluvio y solo se salvan quienes se han posesionados en el Anamei.

\section{Las aves y sus colores}

Este mito del pueblo Minika, contado por la madre de Santiago Yahuarcani e ilustrado por Rember Yahuarcani (2015) cuenta que antes las aves, insectos y peces no tenían color; sin embargo esta gris realidad contrastaba con la belleza colorida de los árboles. Es entonces que a Fídoma, espíritu dueño de la naturaleza, se le ocurre pintar a los animales, para ello se aprovisiona de todo color proveniente de la vegetación: «...empezó a buscar colores las raíces, en los frutos, entre las hojas y en las flores». Con aquellos colores en su cabeza, pintó a los guacamayos, al martín pescador, soldadito cardenal, huanchacos, paucares, tucanes, loros y picaflores. Así las aves dejaron de ser grises para recibir el color de Fídoma, el primer pintor. 


\section{Referencias}

Álvarez, J. (1942). «Mitología, tradiciones y creencias religiosas de los salvajes Hua-rayos». Actas y trabajos cientificos del XXVII' Congreso Internacional de Americanistas, (Lima, 1939), Tomo II. Lima: Librería e Imprenta Gil, S.A., 153-161.

Álvarez, J. (1960). «Folklore huarayo». Misiones Dominicanas, 41, 242. (1960a): 24-30.

Álvarez, J. (1960). «Tradiciones toyeris-huarayas». Misiones Dominicanas, 45, 342 (1960b): 43-48.

Ans, A. y Marcel D'.Ans (1975). La verdadera biblia de los cashinahua. Lima: Mosca Azul,

Chavarría, María C. (1984). Con la voz de nuestros viejos antiguos. Eseha Echiikiana Esoiho. Lima: Lluvia Editores.

Firestone, H. (1991). Gente Ribereña. Estudio de la cultura "Ese ejja». Cochabamba: «Los Amigos del Libro",

Gray, A. (1983). The Amarakaeri: An Ethnographic Account of Harakmbut People Southeastern Peru. (Tesis doctoral).

Gray, A. (1996). Los arakbut. Mitología, espiritualidad e historia. Lima: IWGIA.

Helberg Chávez, Heinrich. Mbaisik, penumbra al atardecer. (Inédito)

Hill, J. (1985). Ed. Rethinking History and Myth. Chicago, Universitu of Illinois Press.

Hissink, K. y Hahn, A. (1961). Die Tacana I. Erzálunsgut...mit einer spanischen und einer englischen Zusammenfassung. Stuttgart: Kenlhammer Verlang.

Hissink, K. у Hahn, (1988). A. Chama-Indianer. Ergebnisse der Frobenius-Expedition nach Boliven 1952 bis 1954. Stuttgart: Franz Steiner Verlag Wiesbadem GMBH.

Jordana, J. (1974). Mitos e historias aguarunas y huambisas de la selva del Alto Marañón. Lima: Retablo de Papel, 1974

Kimura, H. (1981). «La mitología de los ese ejja del oriente boliviano —el dueño imaginario de los animales silvestres». Antropología, Año 2, № 3,: 1-22.

Kloper, P. (1970). La conducta ecológica. México, Editorial Grijalbo,

Le Goff, J. (1991). El orden de la memoria. El tiempo como imaginario. Barcelona: ediciones Paidós.

LÉvi-Strauss, C. (1970). Mitológicas. El origen de las maneras de mesa. Traducción de Juan Almela. México: Siglo XXI,

LÉvi-Strauss, C. (1972a). Lo crudo y lo cocido. México, Fondo de Cultura Económica.

LÉvi-Strauss, C. (1972). Mitológicas. De la miel a las cenizas. Traducción de Juan Almela. México: Fondo de Cultura Económica.

LÉvi-Strauss, C. (1984) El pensamiento salvaje. Trad. Francisco González A. México: Fondo de Cultura Económica.

Ortiz, A. (1973). De Adaneva a Inkarrí; una visión indígena del Perú. Lima: Retablo de Papel. 
Pressman J. (1991). «The mythological origins of avian coloration. Feathers of Blood \& Fire». The gift of birds. Ruben E. Reina y Kenneth M. Kensinger eds. Philadelphia: The University Museum of Archaeology.

Reichel-Dolmatoff, G. (1968). Simbolismo de los Indios Tukano del Vaupés. Bogotá: Universidad de los Andes.

Rivero, W. (1985b). Jahue nia hax jonai... jahue nia cahai. Los indios araona, chacobo y ese ejja de la Amazonia boliviana. Tesis de Licenciatura. Cochabamba: Universidad Católica Boliviana, Santos, F. (1991). The Power of Love: The Moral Use of Knowledge amongst the Amuesha of Central Peru. New Jersey: The Athlone Press.

Urteaga, L. (1991). El Universo sagrado. Lima: Peisa.

Verna, M. (1986). "Sacred Beings of the Ese'ejja». NAOS. Notes and Materials for the Linguistic study of the Sacred, Vol. 2, No 1, (1985-1986) : 9-10.

Yahuarcani, R. y Zeleny, M. (1976). Contribución a la etnografía huarayo (Ecejje). Praha: Universita Karlova Praha. 